\title{
Two sibling species sympatrically breeding: a new conservation concern for the critically endangered Balearic shearwater
}

\author{
Meritxell Genovart ${ }^{1} *$, Javier Juste ${ }^{2} \&$ Daniel Oro ${ }^{1}$ \\ ${ }^{1}$ Institut Mediterrani d'Estudis Avançats IMEDEA (CSIC-UIB), Miquel Marqués 21, 07190, Esporles, \\ Mallorca, Spain; ${ }^{2}$ Estación Biológica de Donãna (CSIC), Avda. Ma Luisa s/n, Aptdo., 41080, Sevilla, Spain \\ (*Corresponding Author: Phone: +1-34-971-611756; Fax: +1-134-971-611761; E-mail: m.genovart@ \\ uib.es)
}

Received 9 July 2004; accepted 4 December 2004

Key words: conservation, mtDNA, shearwater

\begin{abstract}
Two Puffinus shearwater species are endemic to the Mediterranean region: the Yelkouan shearwater $P$. yelkouan breeding in the central and eastern, and the critically endangered Balearic shearwater $P$. mauretanicus in the western, exclusively breeding at the Balearic archipelago. All individuals caught in Minorca, a Balearic breeding site, showed phenotypic traits of Yelkouan shearwaters. Ten birds from that colony were sampled and genetically analysed. A fragment of 857 base pairs of the cytochrome $b$ was sequenced and compared to published sequences of both species obtained from GenBank. A NeighborJoining (NJ) reconstruction distinguished two clades with high bootstrap support, showing that both species bred sympatrically in that colony. This result was unexpected since shearwaters do not usually form mixed colonies. New conservation concerns arise also from our study: at first, breeding population of Yelkouan shearwaters is even smaller than previously thought; additionally, other potential threats emerge, such as hybridization and ecological competition.
\end{abstract}

\section{Introduction}

The taxonomic consideration of the Puffinus shearwaters has been controversial. At first, only one species was described, the Manx shearwater Puffinus puffinus Brünnich 1764 that included the Atlantic form but also all Puffinus from the Mediterranean as a subspecies namely "Levantine". However Mayaud (1932) realized that two Mediterranean forms could be morphologically distinguished in the Mediterranean sea: $P$. puffinus yelkouan, (Cerbi 1927) in the central and eastern Mediterranean, and $P$. puffinus mauretanicus (Lowe 1921) breeding exclusively at the Balearic archipelago (see Figure 1). Both taxa were later separated from the Atlantic form, the Manx shearwater, due to their clear differences in size, morphology, vocalizations, feeding habits, phenology and migratory behaviour (Bourne 1988; Sibley and Monroe 1990; Yésou et al. 1990; Hamer 2003). Later on, osteological (Walker et al. 1990), parasitical (Palma et al. 1997) and molecular analyses (Wink et al. 1993; Heidrich et al. 1998), all supported a further distinction between the two Mediterranean forms. As both taxa were separated by $2.2-2.9 \%$ nucleotide substitutions in the mitochondrial DNA and also they showed different morphological, behavioural and ecological traits, they were finally considered as two distinct species: the Balearic shearwater, Puffinus mauretanicus, and the Yelkouan shearwater, Puffinus yelkouan (Heidrich et al. 1998).

The Balearic shearwater breeds in several colonies at the Balearic archipelago, and although 


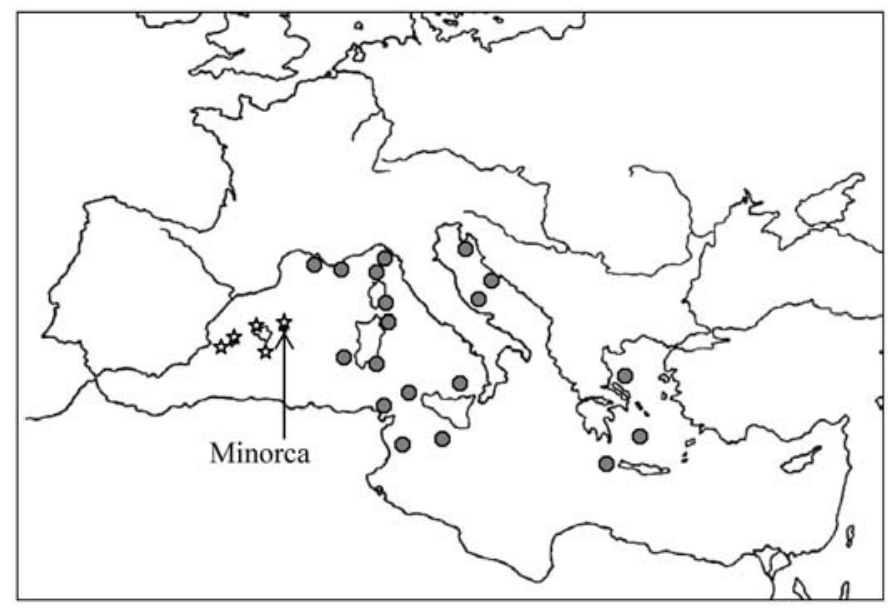

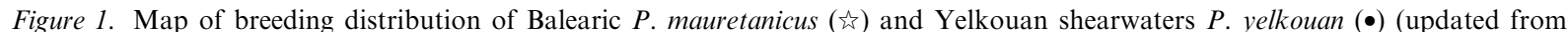
Zotier (1997)).

reliable census are difficult to obtain, the estimate breeding numbers are ca. 1800-2000 pairs (Arcos and Oro 2003). Shearwaters belong to a bird family with high risk of extinction (Lockwood et al. 2000). Very recently an unusually low adult survival has been estimated for Balearic shearwater (Oro et al. 2004) and a severe population regression has been detected (Arcos and Oro 2003). As a consequence, the species has been classified as critically endangered (Oro et al. 2004), the highest conservation category for a species nonextinct in the wild under International Union for Conservation of the Nature (IUCN) criteria.

Recently, it has been described that some shearwaters found at one colony in Minorca, the northern and easternmost island of the Balearic archipelago (see Figure 1), showed Yelkouan shearwaters phenotypic traits (Ruiz et al. 2003). For instance, morphometric comparisons showed significant differences in size between these birds and others from other colonies (Alcover et al. 2003; Ruiz et al. 2003). However, the breeding status of those birds was not assessed and they could be vagrants or prospectors coming from distant origins, a behaviour commonly recorded among Procellariiformes (see revision in Schreiber and Burger 2002). Further, differences in size and phenotypic traits are not always sufficient by themselves to differentiate species, as they could correspond to local polymorphism and/or environmental adaptations as it has been found for other seabirds (Barrett et al. 1985; Ruiz et al. 1998;
Genovart et al. 2003) and even for other shearwaters (Massa and Lo Valvo 1986; Guicking et al. 2004). Consequently, the aim of this study was to analyse genetically Puffinus shearwaters from Minorca, to investigate whether Yelkouan shearwaters are actually breeding in the Balearic archipelago, or on the contrary, the differences in size and phenotypic traits found in Minorca shearwaters correspond to local conspecific variation.

\section{Methods}

Fieldwork was conducted in a colony at Minorca, at the Balearic archipelago $\left(39^{\circ} 55^{\prime} \mathrm{N}, 4^{\circ} 10^{\prime} \mathrm{E}\right)$ (see Figure 1). Ca. 150 breeding pairs are estimated to breed here, in caves and hollows in a calcareous sea cliff (McMinn 2001). Ten individuals were sampled entering the colony during the breeding period, and we could confirm breeding (adult incubating) of 5 of them. All of them showed a pattern colour typical from Yelkouan shearwaters. We took a small blood sample (ca. $25 \mu \mathrm{l}$ ) from a leg vein puncture. Blood was captured with a capillary or syringe and then transferred to a tube containing either preservative buffer (Griffiths et al. 1992) or absolute ethanol. Total DNA was isolated from blood samples by an overnight incubation at $55^{\circ} \mathrm{C}$ in SET buffer (Sambrook et al. 1989) with $30 \mu$ l SDS $10 \%$ and 2.5 units $/ \mathrm{ml}$ of proteinase $\mathrm{K}$ followed by a standard phenol/ chloroform protocol (Sambrook et al. 1989). 
DNA was resuspended in TE buffer (Sambrook et al. 1989). The primer pairs mt-A (L-14970) and mt-Fr (H-16086) given in (Heidrich et al. 1998) and modified from those given by (Kocher et al. 1989) were used to amplify a DNA fragment of the cytochrome $b$ mitochondrial gene.

Amplification reactions were performed in a total volume of $25 \mu \mathrm{l}$ with $1 \mu \mathrm{M}$ of each primer, $0.25 \mathrm{mM}$ dNTP, $1 \times$ Taq buffer, $1 \mathrm{U}$ of Taq DNA polymerase (Bioline), $0.01 \%$ gelatine (USB), $2.5 \mathrm{mM}$ of $\mathrm{MgCl} 2$ and $1-2 \mu \mathrm{l}$ of template DNA. The thermocycling conditions were $94{ }^{\circ} \mathrm{C}$ for $1 \mathrm{~min}$, followed by 35 cycles of $94^{\circ} \mathrm{C}$ for $1 \mathrm{~min}$, $50{ }^{\circ} \mathrm{C}$ for $1 \mathrm{~min}$ and $72{ }^{\circ} \mathrm{C}$ for $1 \mathrm{~min}$, with a final extension of $72{ }^{\circ} \mathrm{C}$ for $5 \mathrm{~min}$. PCR product was purified and concentrated by centrifugal dialysis. We check the amplification and purification results loading $2 \mu \mathrm{l}$ product in a $1.5 \%$ agarose gel. The fragment was sequenced directly from purified PCR product using an ABI 3100 automated sequencer (Applied Biosystems, Warrington, UK). For species identification purposes, our sequences were aligned together with five sequences obtained from GenBank (accession numbers AJ004208, AJ004209, AJ004216, AJ004222 and AY219971), of the closest three shearwater species. We used two sequences of Balearic shearwater, P. mauretanicus, two sequences of Yelkouan shearwater $P$. yelkouan and one sequence of Manx shearwater $P$. puffinus that was used as an outgroup in posterior analyses. Sequences were aligned using CLUSTAL X version 1.8 (Thompson et al. 1997). The best fitting substitution model for our data was selected using hierarchical likelihood ratio test (LRT) implemented in MODELTEST (Posada and Crandall 1998). Then, absolute and corrected genetic distances were estimated using PAUP 4.0b10 software (Swofford 2000) and MEGA version 2.1 (Kumar et al. 2001). A Neighborjoining (NJ) algorithm using the selected substitution model was used to reconstruct phylogenetic relationships among the sequences with PAUP 4.0b10 (Swofford 2000). Robustness of the topology was assessed through bootstrapping (Felsenstein 1985).

\section{Results}

A fragment of 857 base pairs of the cytochrome $b$ was sequenced for the 10 individuals studied. The alignment showed 46 variable sites, 18 of which were parsimony informative for a total of 8 different haplotypes. All unique haplotypes in the cytochrome $b$ fragment are deposited in GenBank (accession numbers AY586997- AY587006).

A HKY85 model (Hasegawa et al. 1985) with no site heterogeneity and an estimated Ts:Tv ratio of 11.08 was selected. Using this model, genetic distances in the cytochrome $b$ fragment varied from $0.00 \%$ to $4.14 \%$ among samples, and the average level of genetic differentiation found between the two shearwater species was $1.6 \%$. NJ reconstruction distinguished two clades with high bootstrap support (see Figure 2). According to the reference sequences, one clade represents the Yelkouan shearwater and the other the Balearic shearwater. Five individuals clustered with the Balearic shearwaters and other five with the Yelkouan shearwaters. Therefore, the analysis confirms the presence of individuals of both shearwater species in Minorca during the breeding period. Among all the birds sampled, three Balearic and two Yelkouan shearwaters were confirmed breeders. Among the eight haplotypes found, five were found within the Balearic shearwater clade and three within the Yelkouan clade.

\section{Discussion}

This is the first record of breeding of Yelkouan shearwater in the Balearic archipelago, which was assumed to be the exclusive breeding range of the critically endangered Balearic shearwaters. It has been estimated that $5 \%$ of the total world population of Balearic shearwaters breeds in Minorca (Ruiz et al. 2003), but results show that this total estimation is even smaller than previously thought (Arcos and Oro 2003).

We also report that Balearic shearwater is also breeding sympatrically in that colony, an unexpected result since mixed colonies among shearwaters are infrequent (Coulson 2002), especially at the level of very close breeding sites. Balearic shearwaters are actually known to segregate spatially from other close species while breeding, apparently to avoid competition for nest cavities (e.g. Aguilar 1997).

The average level of genetic differentiation found between the two shearwater species (1.6\%) is a low genetic distance for an interspecific 


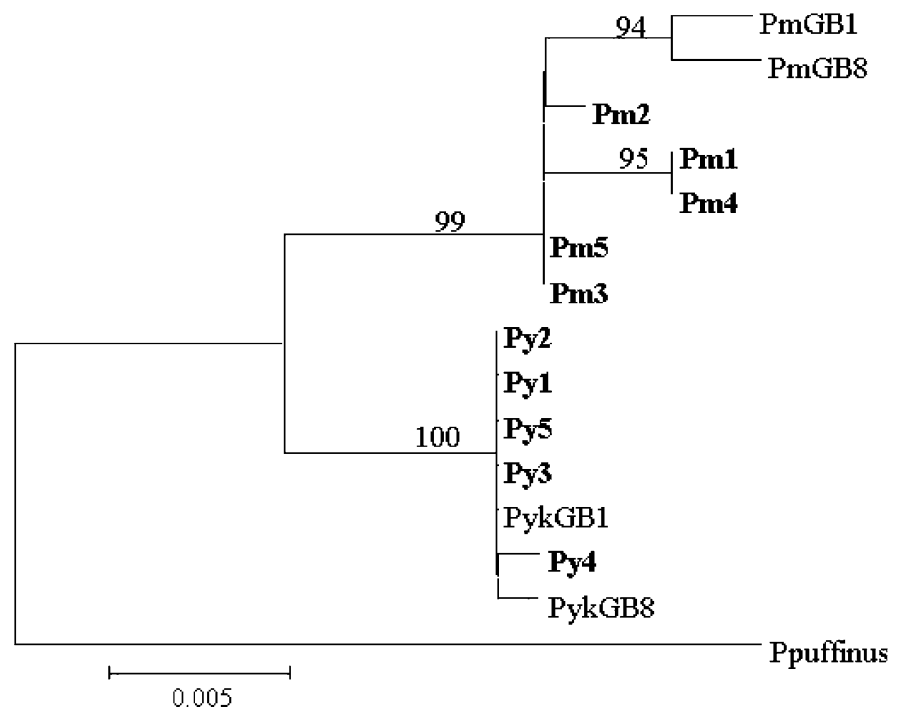

Figure 2. Neighbor-Joining reconstruction of phylogenetic relationships and bootstrap values (after 5000 replicates) between shearwaters of the Mediterranean $(P$. yelkouan $=\mathrm{Py}$, and $P$. mauretanicus $=P m)$ based on $857 \mathrm{bp}$ of the mitochondrial cytochrome $b$ gene, a HKY 85 model, and using Manx shearwater (P. puffinus) as an outgroup. Individuals from Minorca are shown in bold and sequences obtained from Genbank with GB indicated in the sample name.

comparison. This value is even lower than those previously reported by Austin (1996) and Heidrich et al. (1998) for the same two species and for the same mitochondrial fragment. Nevertheless, Austin (1996) has demonstrated low differentiation levels at mtDNA between recognized species within the Puffinus group. Between Yelkouan and Balearic shearwaters we found more than 10 diagnostic nucleotide changes in the cytochrome $b$ fragment, indicating a clear genetic differentiation between both lineages. It is recommended the combination of both traditional characters (as phenotypic or behavioural traits) and DNA techniques in taxonomical arrangements (Proudlove and Wood 2003) and in our case, other phenotypic and behavioural characters support the separation between the two Mediterranean taxa (Sibley and Monroe 1990; Walker et al. 1990; Palma et al. 1997; Yésou and Paterson 1999).

Since only seven individuals from each species were analysed in our study, it seems crucial to undertake a larger genetic study taking into account not only mitochondrial but also nuclear data, and including other colonies from both species to better estimate the distance between species, to analyse the contemporary and historical admixture between them, and finally to evaluate the population genetic structure of both shearwater species.
One of the most important conservation concerns that arise from our study is that hybridisation between these two species could occur. Although hybridisation is relative rare in animals it is quite widespread in some bird taxa (Grant and Grant 1992), and several species of Procellariiforms included the genus Puffinus are actually known to interbreed (Kuroda 1967; Hunter 1983; Pierotti 1987). Hybridisation poses a problem to the conservation point of view, because a species loses in turn its strict identity, or at least has the potential to do so. Consequently hybridisation can threaten a rare species' existence (Rhymer and Simberloff 1996; Allendorf et al. 2001). In this context, the evaluation of a possible introgression by this secondary contact becomes crucial for the conservation of the Balearic shearwater.

Another conservation concern resulting from our study is the possibility of an ecological displacement of the endemic shearwater by this wider distributed incomer. This could be especially critical due to the dramatic loss of suitable breeding sites for the Balearic shearwater in recent times (Arcos and Oro 2003).

This study opens new concerns about the conservation of the Balearic shearwater. As a consequence, comprehensive genetic and ecological studies are urgently required to evaluate the 
interaction between both species and design measures to guarantee the conservation of one of the most endangered endemic bird of the western Palaearctic.

\section{Acknowledgements}

We are very grateful to all people involved in the fieldwork, especially to Rafael Triay, Raül Escandell, Rocío F. Graña, Maite Louzao and Jose Manuel Igual. We would also like to thank people who help us in the laboratory: Joaquín Muñoz, Juanele García-Mudarra and Virginia Rodriguez. This study was partially funded by the Govern de les Illes Balears, Ajuntament de Calvia, and grants from Spanish Ministries of Education and Science (ref. BOS2003-01960) and of Environment (ref. 024B/2002).

\section{References}

Aguilar JS (1997) Biología y conservación de la Pardela Balear, Puffinus mauretanicus. Documents Técnics de Conservació $2^{\mathrm{a}}$ Epoca, 2. Conselleria de Medi Ambient, Ordenació de Territori i Litoral, Palma de Mallorca.

Alcover JA, Genovart M, Igual JM, Lalueza C, Louzao M, Oro D, Palmer M (2003) Estudi comparat entre les poblacions de baldritja Puffinus mauretanicus de Mallorca/ Pitiüses i Menorca. Unpublished Technical Report. Conselleria De Medi Ambient, Govern de les Illes Balears, Palma de Mallorca.

Allendorf FW, Leary RF, Spruell P, Wenburg JK (2001) The problems with hybrids: Setting conservation guidelines. Trends Ecol. Evol., 16, 613-621.

Arcos JM, Oro D (2003) Pardela Balear Puffinus mauretanicus. In: Libro Rojo de las Aves de España (eds. Madroño A, Martí R), SEO/BirdLife and Ministerio de Medio Ambiente, Madrid.

Austin JJ (1996) Molecular phylogenetics of Puffinus shearwaters: Preliminary evidence from mitochondrial cytochromc $b$ gene sequences Mol. Phyl. Evol., 6, 77-88.

Barrett RT, Fieler R, Anker-Nilssen T\& Rikardsen F (1985) Measurements and weight changes of Norwegian adult Puffins Fratercula arcticaand kittiwakes Rissa tridactyla during the breeding season. Ring. Migrat., 6, 102-112.

Bourne WRP (1988) The Yelkouan Shearwater Puffinus (puffinus?) yelkouan Brit. Birds, 81, 306-319.

Coulson JC (2002) Colonial breeding in seabirds In: Biology of Marine Birds (eds. Schreiber EA, Burger J), pp. 87-113. CRC Press, Boca Raton.

Felsenstein J (1985) Confidence limits on phylogenies: An approach using the bootstrap Evolution, 39, 783-791.
Genovart M, Oro D, Bonhomme F (2003) Genetic and morphological differentiation between breeding colonies of Audouin's Gull Larus audouinii. IBIS, 145, 448-456.

Grant PR, Grant RB (1992) Hybridization of Bird Species. Science, 256, 193-197.

Griffiths R, Tiwari B, Becker SA (1992) The identification of sex in the starling Sturnus vulgaris using a molecular technique. Mol. Ecol., 1, 191-194.

Guicking D, Fiedler W, Leuther C, Schlatter R, Becker PH (2004) Morphometrics of the pink-footed shearwater (Puffinus crpatopus): influence of sex and breeding site. $J$. Orn., 145, 64-68.

Hamer KC (2003) Puffinus puffinus Manx shearwater BWP Update, 5, 203-213.

Hasegawa M, Kishino H, Yano TA (1985) Dating of the human-ape splitting by a molecular clock of mitochondrial DNA. J. Mol. Evol., 22, 160-174.

Heidrich P, Amengual JF, Wink M (1998) Phylogenetic relationships in Mediterranean and North Atlantic shearwaters (Aves: Procellariidae) based on nucleotide sequences of mtDNA. Bioch. Syst. Ecol., 26, 145-170.

Hunter S (1983) Interspecific breeding in Giant Petrels at south Georgia $E M U, \mathbf{8 2}, 312-314$.

Kocher TD, Thomas WK, Meyer A, et al. (1989) Dynamics of mithocondrial DNA evolution in animals: Amplification and sequencing with conserved primers. Proc. Natl. Acad. Sci. $U S A$, 86, 6196-6200.

Kumar S, Tamura K, Jakobsen IB, Nei M (2001) MEGA2: Molecular evolutionary genetics analysis software. Bioinformatics, 17, 1244-1245.

Kuroda N (1967) Note on the whitish underparts of Puffinus tenuirostris and a supposed hybrid between $P$. griseus. Misc. Report Yamashina Inst. Ornithol. Zool., 5, 194-197.

Lockwood JL, Brooks TM, McKinney ML (2000) Taxonomic homogenization of the global avifauna. Anim. Conserv., 3, 27-35.

Massa B, Lo Valvo M (1986) Biometrical and biological considerations on the Cory's shearwater Calonectris diomedea. In: Mediterranean Marine Avifauna Population Studies and Conservation (eds. Medmaravis, Monbaillu X), pp. 294-313. Springer-Verlag, Berlin NATO ASI Series Vol. G12.

Mayaud N (1932) Considerations sur la morphologie et la systematique de quelques puffins Alauda, 4, 41-78.

McMinn M (2001) Informe final Life Puffinus mauretanicus, SEO BirdLife, Madrid.

Oro D, Aguilar JS, Igual JM, Louzao M (2004) Modelling demography and extinction risk in the endangered Balearic shearwater. Biol. Cons., 116, 93-102.

Palma RL, Pilgrim RLC, Aguilar JS (1997) Ectoparasites from the Balearic shearwater Puffinus yelkouan mauretanicus. Seabird, 19, 51-53.

Pierotti R (1987) Isolating mechanisms in seabirds Evolution, 41, 559-570.

Posada D, Crandall KA (1998) MODELTEST: testing the model of DNA substitution. Bioinformatics, 14, 817-818.

Proudlove G, Wood PJ (2003) The blind leading the blind: Cryptic subterranean species and DNA taxonomy. Trends Ecol. Evol., 18, 272-273.

Rhymer JM, Simberloff D (1996) Extinction by hybridization and introgression. Annu. Rev. Ecol. Syst., 27, 83-109. 
Ruiz A, McMinn M, Martí R (2003) Pardela Mediterránea Puffinus yelkouan. In: Atlas de las aves reproductoras de España (eds. Martí R, Del Moral JC), pp. 90-91. Dirección General de Conservación de la Naturaleza-Sociedad Españolade Ornitologia, Madrid.

Ruiz X, González-Solís J, Oro D, Jover L (1998) Body size variation in Audouin's Gulls Larus audouinii: A densitydependent effect? IBIS, 140, 431-438.

Sambrook J, Fritsch EF, Maniatis T (1989) Molecular Cloning: A Laboratory Manual, Cold Spring Harbor Laboratory Press, New York.

Schreiber EA \& Burger J (2002). Biology of Marine Birds. CRC Press.

Sibley CG, Monroe BL (1990) Distribution and taxonomy of the birds of the world, Yale University Press, New Haven, CT.

Swofford D. Paup 4.0. [b10]. (2000). Sinner Associates.

Thompson JD, Gibson TJ, Plewniak F, Jeanmougin F, Higgins DG (1997) The Clustal X windows interface: Flexible strat- egies for multiple sequence alignment aided by quality analysis tools. Nucl. Acids Res., 24, 4876-4882.

Walker C, Wragg G, Harrison C (1990). A new Shearwater from the Pleistocene of the Canary Island and its bearing on the evolution of certains Puffinus Shearwaters. Hist. Biol. 3.

Wink M, Heidrich P, Ristow D (1993) Genetic evidence for speciation of the manx Puffinus puffinus and Mediterranean shearwater Puffinus yelkouan. Vogelwelt, 114, 226232.

Yésou P, Paterson AM (1999) Puffinus yelkouan et Puffin des Baléares: une ou deux espécies. Ornithos, 6, 20-31.

Yésou P, Paterson AM, Mackrill EJ, Bourne WRP (1990) Plumage variation and, identification of the "Yelkouan Shearwater". Brit. Birds, 83, 299-317.

Zotier R (1997). Biogeographic des oiseaux marins en Mediterranee et Ecologic d'un Procellariiforme endemique: Le Puffin de mediterranee Puffinus yelkouan. Université Montpellier II. 